\title{
Automatic Counting and MSG Sending using GSM
}

\author{
Dr. J. R. Panchal ${ }^{1}$, Nikita Jadhav ${ }^{2}$ \\ Associate Professor, Department of E\&TC, DACOE, Karad ${ }^{1}$ \\ Student, Department of E\&TC, DACOE, Karad ${ }^{2}$
}

\begin{abstract}
The Automatic counting and MSG sending using GSM system is most widely used in industries. Automatic bag counting offers extreme advantages over traditional off determining what product has been received at the godown. In this system also detect defected bags. And defected bag is automatically removed by using shaft. Manually it is not possible to find defected bags so this is good advantage to this system. If weight of bag is less than the considered weight then weight sensor sense it and defected bag is found and immediately shaft will remove that defected bags and after detection bag will automatically counted by laser sensor. Manual counting is very time consuming process. The basic purpose of automatic counting and MSG sending using GSM module system is bags are counted automatically and MSG will be send to mobile of supervisor in specific period. It is most efficient system for counting bags. The PIC16F877 controller provides counting product automatically and also help to find defected bags accurately. The laser sensor makes the system efficient.
\end{abstract}

Keywords: PIC16F877, laser sensor, weight sensor, shaft, GSM module.

\section{I.INTRODUCTION}

In automatic counting and MSG sending using GSM module system bags are counted automatically and MSG will be send to mobile. Purpose of this project is to avoid manual work of counting bags. Due to this we can reduce manual work and increase accuracy of work by doing this we can increase the profit of industry. By using weight sensor system will find defected bags and remove by using shaft. In various industries, market application we use such type of counting machine.

In the system PIC16F877 controller is used. It supports analog to digital conversion function and also consumes low power. There is a laser sensor is used for automatic counting of any product packets. When bags cut the light coming from laser sensor then count is increased by one. Buzzer is applied for indication. It also includes real time clock (RTC) for 24 hour accurate counting purpose. MAX232 IC establishing serial communication between PIC16F877 controller and GSM. After completion of 8 hours counting numbered MSG are send to the mobile of supervisor through GSM module[4]. LCD is also include in the system for displaying counted number of bags. Counted numbers are stored on erasable programmable read only memory. Worker not count large number of bags accurately in a single day.[2]

\section{II.PROPOSED SYSTEM}

\section{A. Software}

The software part is based on keil $\mu$ vision 4 .

i. Keil $\mu$ Vision 4

Keil c compiler for the microcontroller is most popular compiler in the world. It provide more features that is it provide complete symbol and type information for sourcelevel debugging.

\section{B. Hardware}

i. PIC16F877 controller

PIC controller have Harvard organization of memory. In PIC number of data lines for data memory and a program Memory are different.

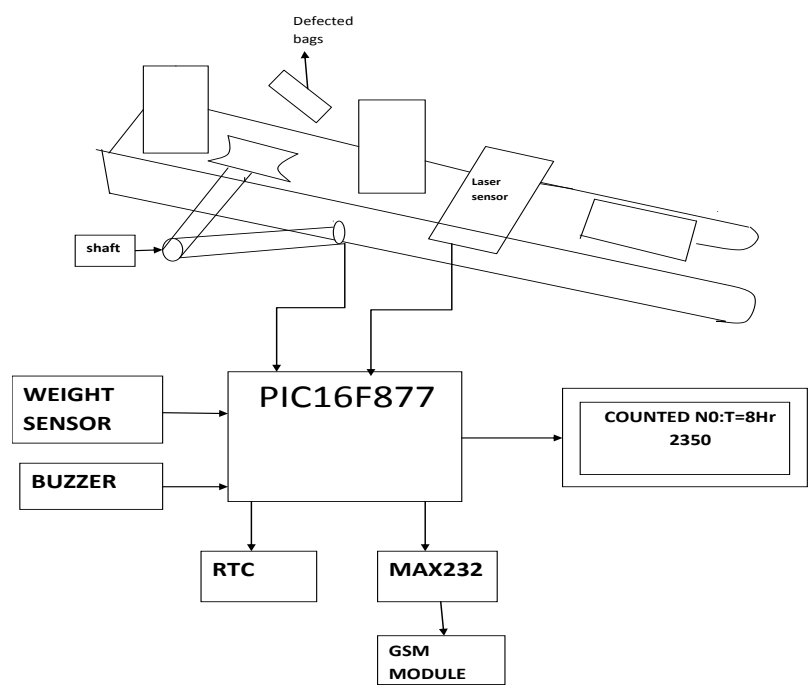

Fig.1 Block diagram of Automatic counting and MSG sending using GSM

Also the number of address lines for program and data are different. PIC uses 14 bits for instructions which allows for all instructions to be one word instructions. It have 
high performance CISC processors. It consist only 35 instruction set. PIC microcontroller has a built in poweron-reset. PIC supports analog to digital conversion function. It consumes low power. The PIC16F877 has a brownout reset. Whenever the supply voltage drops below 4 volt brownout feature causes reset of microcontroller. It allows serial programming.

\section{ii. Laser sensor}

Laser sensor are allowing to detect and to measure distance to a target without the need of reflective material. The laser sensor can be aligned to the target from practically any distance or any angle within its range. Laser sensor will also return an accurate measurement to more difficult targets, including the most liquids and solids. Laser sensor are eye safe. Make non-contact and non-instructive measurement without the need of frequent calibration. Recognizes small target at large distances, within narrow openings. Perform under temperature variation, background noise, acoustically absorbing materials.

\section{iii. Real Time Clock(RTC)}

RTC provide required time and date in many applications such as clock, staff attendance system and alarm etc, that keep track on current time and provide consistent result to performed task. In RTC chip A0, A1, A2 are address pins, VCC and GND are supply and ground pins respectively. VBT is a battery power supply pin. For synchronize data on serial interface SCL serial pin used. For transmit and receive the data on serial interface SDL pin is used. Clock Out is an optional square wave output pin.OSC0 and OSC1 are crystal oscillator pins which are used to provide the clock signal to the RTC device.

\section{iv. MAX232}

MAX232 is designed by Maxim integrated products , this IC is widely used in RS232 communication system in which the conversion of voltage level is required to make TTL device to be compatible with pc serial port and vice versa. The $+5 \mathrm{v}$ power supply required for MAX232 and the output of this MAX232 is \pm 7.5 volts. It can be work as a hardware layer converter for two system to communication simultaneously. MAX 232 used in 16 pin DIP packets. In MAX232 TTL logic 0 is defined by 0 volt and 1 is defined by 5 volt. MAX 232 requires minimum 4 external capacitors. The capacitor are used depending upon the application.

\section{v. GSM module}

GSM is mobile communication modem. It is stands for global system for mobile communication. GSM modem is a specialized type of wireless modem. A GSM modem accepts a SIM card and operates just like a mobile phone because it is wireless network. A GSM modem works as like of the dial-up modem. The dial-up modem sends and receives the data through fixed telephone lines and GSM modem sends and receives data through radio waves. While these GSM modem one most frequently used to provide mobile internet connectivity can also be used for sending and receiving SMS and MMS messages. GSM services operates at the $850 \mathrm{MHz}, 900 \mathrm{MHz}, 1800 \mathrm{MHz}$ and $1900 \mathrm{MHz}$ frequency band. The digital system carry $64 \mathrm{kbps}$ to $12 \mathrm{Mbps}$ data rates.

\section{vi. Weight sensor}

Weight sensor is also known as load cell. It is a transducer which is used to create an electrical signal whose magnitude is directly proportional to the force being measured. If weight of bags are less than $50 \mathrm{~kg}$ then weight sensor sense it. And give information to PIC about weight. PIC controls shaft and removes defected bags.

vii. LCD display

LCD stands for liquid crystal display. Counted numbers are displayed on LCD. LCD comes in many sizes such as $8 \times 2,16 \times 2,20 \times 4$ etc all the LCD's perform the same functions. Their programming is also same and all have same 14 pins $(0-13)$ or 16 pins $(0-15)$. LCD have 8 data pins which carry 8 bit data or command from external unit such as PIC16F877. It requires VCC 5 volt power supply and GND connected to ground. LCD pin also includes V0 to set LCD contrast, RS (register select) there are two registers in LCD i) command register ii) data register. When $\mathrm{RS}=0$ then command register is selected otherwise data register is selected. It also includes RW (read-write) and EN (enable signal). When $\mathrm{RW}=1$ we want to read data from LCD otherwise we want to write to LCD.

Table no.1: Survey for counted number of bags in one day.

\begin{tabular}{|l|c|c|c|}
\hline Time & bags & $\begin{array}{l}\text { Defected } \\
\text { bags }\end{array}$ & $\begin{array}{l}\text { Total } \\
\text { counted bags }\end{array}$ \\
\hline 1 hour & 250 & - & 250 \\
\hline 2hour & 200 & 1 & 199 \\
\hline 3hour & 325 & - & 325 \\
\hline 4hour & 175 & - & 175 \\
\hline 5hour & 400 & 1 & 399 \\
\hline 6hour & 375 & - & 375 \\
\hline 7hour & 200 & - & 200 \\
\hline 8hour & 425 & - & 425 \\
\hline Total & 2350 & 2 & 2348 \\
\hline
\end{tabular}

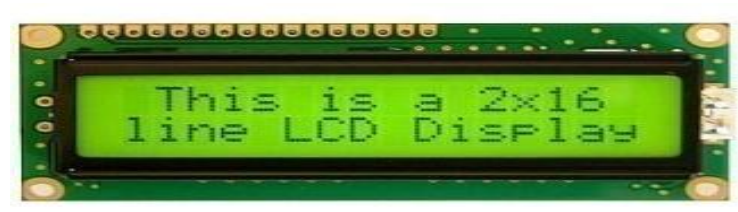

Fig no. 2 LCD Display

\section{FUTURE SCOPE}

This project can be used in sugar industry for counting sugar bags. This project also used in paper industry for counting papers. It also used in cash counter for counting notes and as future scope for detecting the fake notes. This 
project also detect faulty bags and remove through shaft. This project will automatically recycle faulty bags.

\section{ADVANTAGES}

Our project is helpful for time saving. Due to our project bags are counted much faster rate than human. It takes only a few seconds for the machine to count and there is no need for the user to recheck the figure and waste times. Our project gives accurate results. A human may make an error while counting bags manually. Counting machines offer maximum convenience to the user. And also detect faulty bags. This automatic counting machines come with an additional display unit for convenience.

\section{CONCLUTION}

By doing automatic counting and message sending using GSM project we count the accurate number of bags automatically and sending bag numbers on to the mobile of supervisor. The bags counting machine counts bags at a much faster rate than human. The counting machine gives exact results. It is one of most successful technique that have been used in industry.

\section{REFERENCE}

[1] Crystalynne D. Cortez, Jaswinder S. Badwal, Jocelyn R Hipolito, Ditche Jane C. Astillero, Melvie S. Dela Cruz, And Jaira C, Inalao. Development Of Microcontroller-Based Biometric Locker System With Short Message Service, May 2016.

[2] Prof. Trupti K, Prof Rajashree , R. Shinde, GSM Based Digital Fuel Meter And Fuel Theft Detection Using PIC Controller.International Journal Of Advanced Research In Science, Engineering And Technology Vol.3 Issue 4, April 2016.

[3] AderemiA.AtayeroAndAdeyemiS.Alatishe, Members, IAENG "Design and Construction of a Microcontroller Based Automatic Irrigation System.Proceedings of the World Congress on Engineering and Computer science, OCT 2015.

[4] Subhajit Dey, Tamaghna Kunda, sourav Mukherjee \&MiliSarkar. WEB Based Real-Time Home Automation And Security System. International Journal Of Electrical And Electronic Engineering \& telecommunications .ISSN2319-2518 Vol 4,No.3,July 2015.

[5] Joshua Abolarinwa, Abubakar JSAH Leonardo,Design And Implementation Of Microcontroller Based Automatic Sequence Counting And Switching System. Electronic Journal Of Practices \& technologies .Issue 26,June 2015.

[6] Sana M. Fakir, GayatriS.Shirsat, JyotiV.Sutar, MadhukarS.Chavan.Efficient Implementation Of Auto Control System Using PIC16f877a For Small Scale Industries. International Journal Of Advanced Scientific and Technical Research. Issue 5 Volume 2, March-April 2015.

[7] MustafijuzRahman,A.H.MZadidulKarim, SutanurNyeem, faisal khan, GolamMatin.Microcontroller Based Home security \& Load Controlling Using GSM Techonolgy.I. J. Computer Network \& Information Security Vol. 7, No. 4 March 2015.

[8] Abdullah Al Asad, Al Muzuzahid ,S. faruk.Design And Development Of SMS Based Wireless Home Appliance Control And Security system. Journal Of Modern Science And Technology Vol 3.No 1,March 2015.

[9] TejaVardhan Reddy., Dr. K. sreenivasa Ravi. A Smart Home Security System Based On 3G. International Journal Of Advanced Research Volume 2,Issue 2,Issue7 2014.

[10] Mamun, A.L., Ahmed, M., Alqahtani, M., Altwijri, O., Rahman, M., Ahmed, N.U., Rehman, S.A.M.M., Ahmed, Rb., Sundaraj, K.A Microcontroller -Based Automatic Heart Rate Counting System
From Finger Tip. Journal Of Theoretical And Applied Information Technology, April 2014. 